\title{
Defects detection on the welded reinforcing steel with self- shielded wires by vibration tests
}

\author{
Ion Crâş̧tiu $^{1 *}$, Eva Nyaguly $^{2}$, Sorin Deac ${ }^{3}$, Mircea Vodă ${ }^{4}$, Dorin Simoiu ${ }^{5}$, Liviu Bereteu ${ }^{6}$ \\ ${ }^{1}$ Politehnica University Timisoara, ion_crastiu@upt.ro, Romania \\ ${ }^{2}$ Politehnica University Timisoara, pintiutza@gmail.com, Romania \\ ${ }^{3}$ Politehnica University Timisoara, sorin.deac@upt.ro, Romania \\ ${ }^{4}$ Politehnica University Timisoara, mircea.voda@upt.ro, Romania \\ ${ }^{5}$ Politehnica University Timisoara, dorin.simoiu@upt.ro, Romania \\ ${ }^{6}$ Politehnica University Timisoara, liviu.bereteu@upt.ro , Romania
}

\begin{abstract}
The aim of this paper is the development and validation of a vibroacustic technique to welding defects detection, especially for welded reinforcing structures. In welded structures subjected to dynamic cyclic loads may appear and propagate fatigue cracks due to local structural damage. These cracks may initiate due to the technological parameters used in welding process, or due to environmental operating conditions. By the means of Finite Element Method (FEM), the natural frequencies and shape modes of more welded steel specimens are determined. The analysis is carried out in undamaged condition as well as damaged one, after artificially induced damages. The experimental measurement of the vibroacustic response is carried out by using a condenser microphone, which is suitable for high-fidelity acoustic measurements in the frequency range of $20-20.000 \mathrm{~Hz}$. The vibration responses of the welded specimens, in free-free conditions, are carried out using algorithms based on Fast Fourier Transform (FFT), and Prony's series. The results are compared to modal parameters estimated using FE Analysis.
\end{abstract}

\section{Introduction}

Reinforced concrete is a composite material in which the tensile strength and the ductility are balanced by the inclusion of the concrete reinforcements to give the tensile strength and/or ductility higher than that of concrete. The reinforcement is usually, though not necessarily, made of steel bars, called reinforcements, and is embedded passive in concrete. Reinforcement schemes are generally designed to withstand concrete in certain regions where tensile stresses may cause cracks unacceptable and/or structural failure. Modern reinforced concrete as a reinforcing material can contain a variety of steel, polymer or composite materials. The metal can alternate with composite materials. Reinforced concrete may also be subjected to the permanent compression, so as to improve the structural behavior under work load. The most common methods for achieving this state of pre and post-application are the straining.

Weldable reinforcing steel and stainless reinforcing steel, in accordance with the relevant standards or technical specification may be used. For refurbishment and extensions of buildings, the weldability of the existing reinforcing steel shall be verified. Other types of steels, weldable structural or stainless steels, may be welded to reinforcing steel, SR EN 481-1/2012 [1], and M. Burcă and St. Negoiţescu [2].

In this paper we determine the changes of resonance frequencies of welded reinforcing steel bars PC 52 with surface defect using a nondestructive technique based on experimental determination of resonance frequencies, $\mathrm{L}$. Bereteu, M. Burca, R. Moisa, D. Simoiu, Gh. Draganescu, St. Pavel, and C. Nes [3], L. Bereteu, M. Voda, T. Medgyesi, Gh. Draganescu and D. Simoiu [4].

The results are used to introduce three quality indicators of the welding, about the name of analysis method.

\section{Materials and methods}

\subsection{Samples obtaining}

Reinforcing steel PC 52 is a low alloy steel with a periodic profile. The chemical composition of the steel

\footnotetext{
"Corresponding author: ion crastiu@upt.ro
} 
grade is as follows: maximum $0.22 \% \mathrm{C}$; maximum $0.55 \% \mathrm{Si}$; than $1.6 \% \mathrm{Mn}$; maximum $0.045 \% \mathrm{~S}$; maximum $0.045 \% \mathrm{P}$ and $0.06 \% \mathrm{Ti}$ or $\mathrm{Nb}$ maximum. Preparation of the ends of bars and choice of joints form were made according to norm SREN 438/1-2012 [5] for concrete steel bars with a diameter greater than $16 \mathrm{~mm}$. The norm is applicable for welding weldable steel bars and concrete that can transmit loads. The legislation specified requirements for materials, design and construction, welded joints, and quality requirements. Welding processes are given which can realize concrete reinforcement welded steel.

To obtain the samples was chosen arc welding process together with or without the root, and in the process of arc welding fittings was chosen tubular wire welding with self protection. Butt welding fittings concrete can be done without root support if the diameter of the steel bar is more than $16 \mathrm{~mm}$, respectively with root support if bar diameter is greater than $12 \mathrm{~mm}$.

\subsection{Resonant vibration tests}

In the following, the samples consist of welded reinforcing steel, shall be considered circularly bars, having a constant section, and no subject to external tensions. To study the free vibration of these bars can consider different boundary conditions. The best known cases in the literature are: free - free conditions.

\subsection{Free-free vibration of welded reinforcing steel bars}

Vibratory motion of the bar is governed by a differential equation with partial derivate EulerBernoulli as in Meirovitch [6]:

$$
\mathrm{EI} \frac{\partial^{4} \mathrm{v}}{\partial \mathrm{x}^{4}}+\rho \mathrm{A} \frac{\partial^{2} \mathrm{v}}{\partial \mathrm{t}^{2}}=0,
$$

where : E is Young's modulus, I is the geometric moment of inertia of the cross-sectional area, A is the area of this section, and $\rho$ is material density. With $\mathrm{v}(\mathrm{x}$, t) was noted the transverse deflection of the bar at a distance $\mathrm{x}$ from the end. To determine the transverse vibrations of the specimen must be known boundary conditions. In the physical model developed was assumed a free-free bar.

In table 1 are calculated the characteristic equation and the first five solutions on the free-free boundary conditions for the flexural vibration.

Table 1. The characteristic equation and the five solutions

\begin{tabular}{|l|c|c|c|c|c|}
\hline $\begin{array}{l}\text { Characteristic } \\
\text { equation }\end{array}$ & $X_{1}^{2}$ & $X_{2}^{2}$ & $X_{3}^{2}$ & $X_{4}^{2}$ & $X_{5}^{2}$ \\
\hline $1-\operatorname{ch} x \cos \mathrm{x}=0$ & 22.4 & 61.7 & 120.9 & 199.8 & 298.5 \\
\hline
\end{tabular}

In this table was noted:

$$
\mathrm{X}_{\mathrm{r}}=\lambda_{\mathrm{r}} \mathrm{L} \text {, }
$$

$$
\lambda_{\mathrm{r}}=\sqrt[4]{\frac{\rho \mathrm{Ap}}{\mathrm{EI}}},
$$

and $\mathrm{r}=1,2 \ldots .5$, represent the number of the natural mode.

From (3) there are obtained the natural frequencies:

$$
\mathrm{f}_{\mathrm{r}}=\frac{\mathrm{X}_{\mathrm{r}}^{2}}{2 \pi \mathrm{L}^{2}} \sqrt{\frac{\mathrm{EI}}{\rho \mathrm{\rho A}}} .
$$

where, $X_{r}$ are the routs of the characteristic equation Euler - Bernoulli, table I. If the cross area and geometric moment of inertia are modified by surface defect, the natural frequencies becomes

$$
\mathrm{f}_{\mathrm{r}}^{\prime}=\mathrm{f}_{\mathrm{r}}-\frac{1}{2 f_{\mathrm{r}}} \frac{\{\mathrm{X}\}_{\mathrm{r}}^{\mathrm{T}}[\Delta \mathrm{K}]\{\mathrm{X}\}_{\mathrm{r}}}{\{\mathrm{T}]\{\mathrm{X}\}_{\mathrm{r}}},
$$

where $[\Delta \mathrm{K}]$ is stiffness structural modification matrix and $[\mathrm{M}]$ is mass matrix, L. Bereteu [7].

\subsection{Finite Element Analysis}

To validate the shape of vibration modes of the sample and correlation with resonance frequencies experimentally obtained is necessary to make a modal analysis. The modal parameters are obtained by Finite Element Analysis using ANSYS.The shape and size of the sample are given in Fig.2.

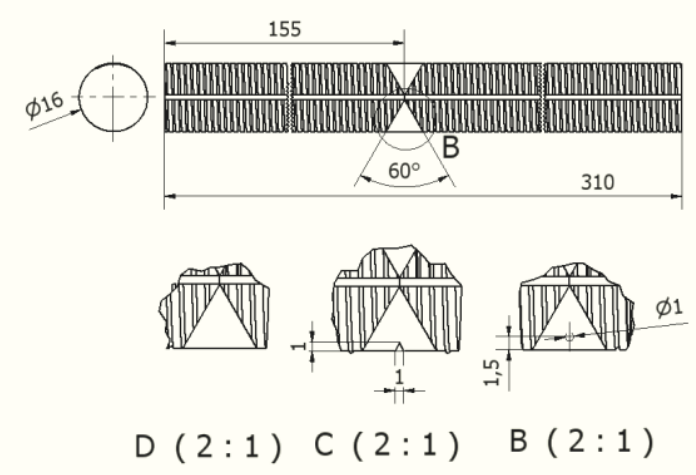

Fig. 1. The shape and size of the experimental sample

\section{Experimental setup}

The experimental stand for non-contact measurement of free vibrations of the sample is shown in Fig. 2. and it is composed by: the sample 1 , which is the mechanical structure to be analyzed; impulsive mini hammer 2; brackets to support the sample 3; elastic threads for support of the structure in boundary conditions with the free ends 4; the acoustic sensor one condenser microphone 5 , and the computer that has embedded and acquisitions plate 6 .

where $\lambda$ is:

$\overline{\text { * Corresponding author: ion_crastiu@upt.ro }}$ 


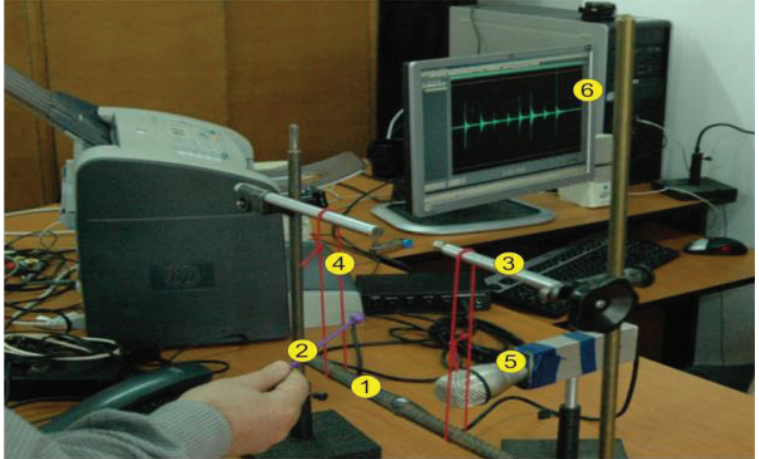

Fig. 2. Experimental stand for vibroacustic measurements

\section{Numerical results}

The sizes mechanical characteristics of the PC 52 steel bar analyzed by ANSYS software are: $\mathrm{L}=310 \mathrm{~mm}$, $\phi=16 \mathrm{~mm}, \quad \rho=7850 \mathrm{~kg} / \mathrm{m}^{3}$ and $\mathrm{E}_{1}=200 \mathrm{GPa}$. The frequencies and the shape modes of the sample without any defect are given in table 2 , and the frequencies and the shape modes of the sample with surface defect are given in the table 3 .

\section{Experimental results}

To determine the resonance frequencies of reinforcing bars without any surface defect and with induced surface defect, Fast Fourier Analysis are required for two signals. Signal acquired for reinforcing bar without surface defect is shown in Fig. 3.

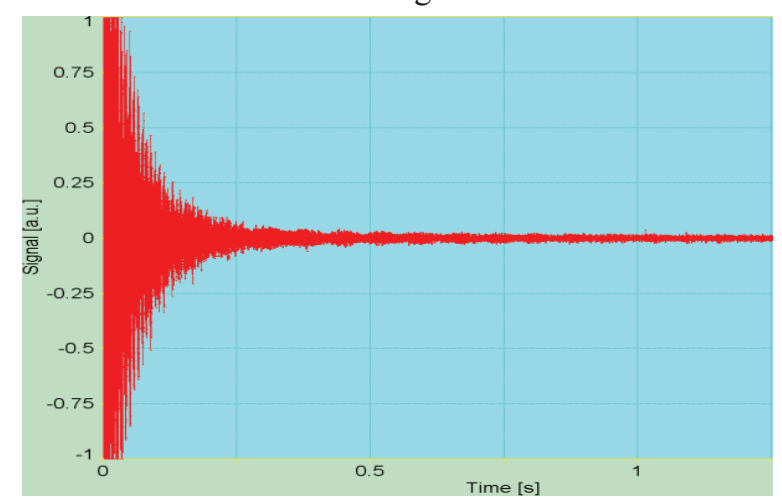

Fig. 3. Experimental acquired signal

A similar signal is obtained for a bar with surface defect induced. The two signals are processed using Fast Fourier Transform method, S.W.Park [8] and Prony's series method, D.J. Trudnowski [9]. The Fourier Frequency Spectrum in $0 \mathrm{~Hz}$ to $4000 \mathrm{~Hz}$ for without defect bar in the Fig. 4 is presented. A similar spectrum, but with changes in natural frequencies, it was obtained for surface defect induced bar.

To characterize weld quality depending on the method used to determine the resonant frequencies three indicators are introduced. The first indicator shows the relative deviation of the resonance frequencies of the bar
Table 2. The first six frequencies and the mode shape of the bar without dfect

\begin{tabular}{|l|l|l|}
\hline \multicolumn{1}{|c|}{ Mode } & $\begin{array}{c}\text { Frequency } \\
{[\mathrm{Hz}]}\end{array}$ & \\
\hline 1.bending & 718 & \\
\hline 2.bending & 754 & \\
\hline 3.bending & 1946.7 & \\
\hline 5.bending & 2000.8 & \\
\hline 6.torsion & 3917.2 & \\
\hline
\end{tabular}

Table 3. The first six frequencies and the mode shape of the bar with surface dfect

\begin{tabular}{|l|l|l|}
\hline \multicolumn{1}{|c|}{ Mode } & $\begin{array}{c}\text { Frequency } \\
{[\mathrm{Hz}]}\end{array}$ & \\
\hline 1.bending & 717.1 & \\
\hline 2.bending & 752.4 & \\
\hline 3.bending & 1943.5 & \\
\hline 4.bending & 2019.2 & \\
\hline 6.torsion & 3911.7 & \\
\hline
\end{tabular}

without defect compared with resonant frequencies of the bar with surface defect. The frequencies were obtained based on Modal Analysis Method using the Finite Element Method. Finite Element Method Indicator (FEMI) is defined as

$$
\text { FEMI } \%=\frac{\mathrm{f}_{\mathrm{rFEM}}-\mathrm{f}_{\mathrm{rFEM}}}{\mathrm{f}_{\mathrm{rFEM}}} \cdot 100,
$$

where $f_{r_{\text {FEM }}}$ is the $r$-th mode frequency of the bar without defect and $\mathrm{f}_{\mathrm{rFEM}}$ is the $\mathrm{r}$-th mode frequency of the damaged bar. Similarly the other two indicators are introduced: Fast Fourier Method Indicator (FFMI) as,

$$
\text { FFTMI } \%=\frac{f_{\text {rFFTM }}-f_{\text {rFFTM }}^{\prime}}{f_{\text {rFFTM }}} \cdot 100,
$$

and Prony Method Indicator (PMI) as

$$
\mathrm{PMI} \%=\frac{\mathrm{f}_{\mathrm{rPM}}-\mathrm{f}_{\mathrm{rPM}}^{\prime}}{\mathrm{f}_{\mathrm{rPM}}} \cdot 100
$$


where the frequencies marked with an apostrophe ( ' ) are denoted bar modes frequencies with surface defects, and without ( ' ) the frequencies of the undamaged bar.

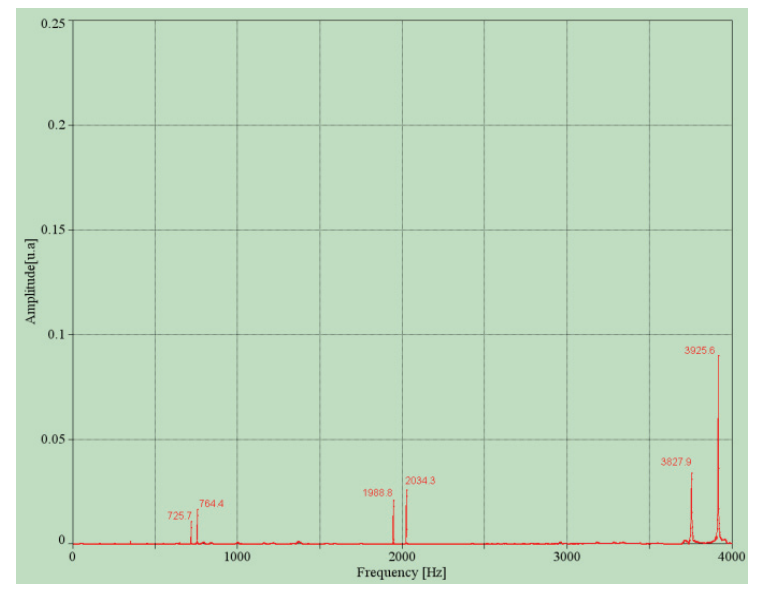

Fig.4. Fourier Frequency Spectrum for undamaged bar

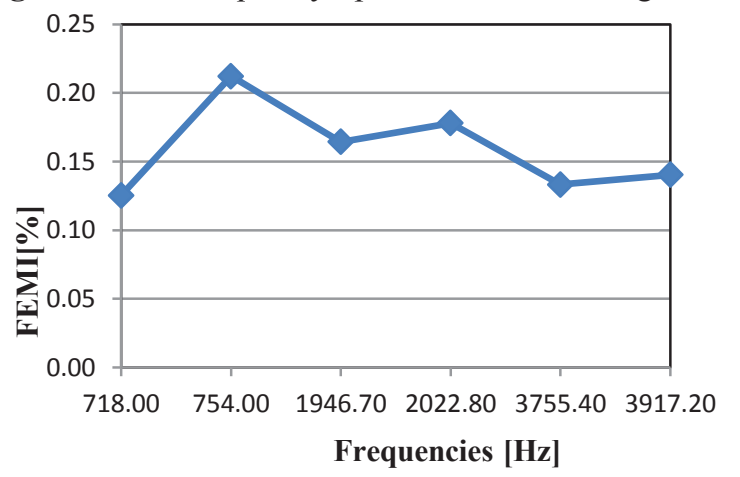

Fig. 5. FEM indicator by frequency

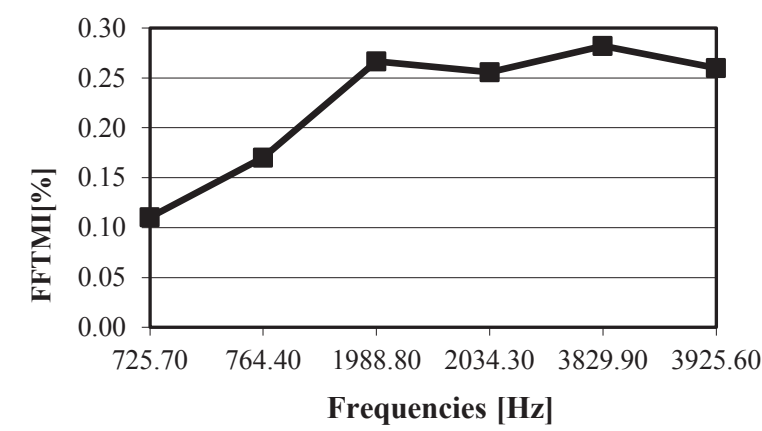

Fig.6. FFT indicator by frequency

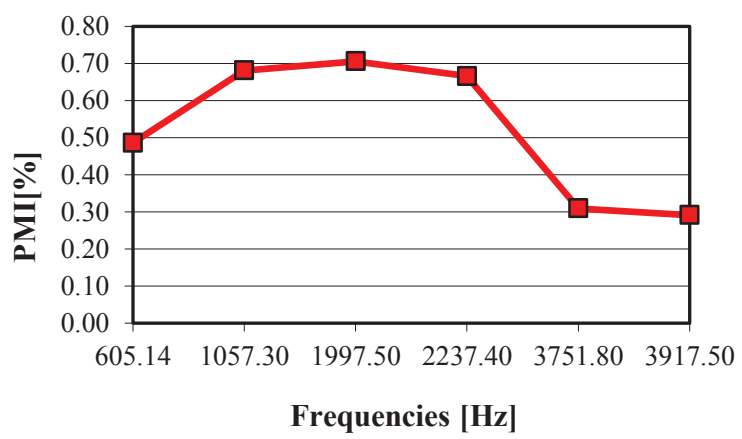

Fig. 7. PM indicator by frequency
FEM indicator depending on the frequencies of the first six modes of bar vibration is shown in Fig.5. Change in other two indicators, according to the resonance frequencies are given in Figs. 6 and 7.

\section{Conclusions}

The results obtained in this work show that the signals and data analysis method for free vibration of the samples can be considered between nondestructive methods that can be used to determine the quality of the welding. The changing of resonance frequencies through structural modifications as a consequence of welding defects obtained in experiments come to validate the numerical results obtained on modal analysis by FEM, and the results obtained by applying the formulas (5). There is a good convergence of results obtained by the two methods of experimental analysis of signals: Prony's Series Method and Fast Fourier Transform Method, compared with numerical method (FEM). It finds that the three indicators give a weak sensitivity for a surface defect, especially for first resonant frequency of vibration. However, the sensitivity is double or even triple for higher frequencies mode of vibration. The best stability is given for high resonance frequencies of the modes by FFT Indicator.

\section{References}

[1] SR EN 481-1/2012, Welding - Welding of Reinforcing Steel.

[2] M. Burcă, St. Negoițescu, MIG/MAG Welding (in romanian), Editura SUDURA, Timișoara, 2004

[3] L. Bereteu, M. Burca, R. Moisa, D. Simoiu, Gh. Draganescu, St. Pavel, C. Nes, "Determination of some mechanical properties of welded reinforcing steel with self-scielded wires by vibration tests", Advanced Material Research, Vol 1029, pp 206-211, 2014.

[4] L. Bereteu, M. Voda, T. Medgyesi, Gh. Draganescu, D. Simoiu, "Defect detection on the welded thin steel plates using vibroacustic method", Advanced Material Research, Vol 1029, pp 212-217, 2014

[5] SR 438-1/2012, Steel Products for Concrete Reinforcement. Part 1. Hot rolled Structural Steel, Grades and Technical Quality Requirements.

[6] L. Meirovitch, Fundamentals of Vibrations, Waveland Press, Inc. 2010

[7] L. Bereteu, The vibrations of mechanical structures (in romanian), Editura Mirton, Timisoara, 2000

[8] S.W.Park, "Analytical Modeling of Viscoelastic Dampers for Structural and Vibration Control", Int. J. Solids Struct. 38, pp 8065-8092, 2001

[9] D.J. Trudnowski, Characteristics of Identifying Linear Dynamic Models Response Data Using Prony Analysis, Battelle, 1992.

\footnotetext{
${ }^{*}$ Corresponding author: ion_crastiu@upt.ro
} 